\title{
Constraints on definite article alternation in speech production: To "thee" or not to "thee"?
}

\author{
M. GARETH GASKELL, HELEN COX, KATHERINE FOLEY, HELEN GRIEVE, and RACHEL O'BRIEN \\ University of York, York, England
}

\begin{abstract}
A recent study showed that the pronunciation of the definite article in English (as either a reduced "thuh" or an unreduced "thee") depends on a number of different factors, including the pronunciation, spelling, and stress assignment of the following word (Raymond, Fisher, \& Healy, 2002). However, it is not clear from previous research whether these factors influenced performance implicitly in normal speech production or whether explicit knowledge of the object of the experiment was relied on. In Experiment 1, we examined implicitperformance on pronunciation of the definite article and found more systematic behavior than had previously been observed but, again, an influence of the pronunciation, spelling, and stress assignment of the following word. In Experiment 2, we tested the influence of the following word on definite article production during language development for two groups of children 8 and 10 years of age. This experiment showed increasing use of the unreduced form during development and a further influence of orthography. We interpret these results in terms of an interaction between perception and production in which the production system makes use of generalizations on the basis of both phonological and orthographic representations generated in perception.
\end{abstract}

A major research goal in psycholinguistics has been to understand the way morphological systems operate in language perception and production. Entirely regular morphological systems are rare, with the more normal situation being one in which exceptional items or classes of alternatives exist. The familiar example on which much research has been based is the past tense of English. This normally involves the concatenation of the allomorphs $/ \mathrm{t} /, / \mathrm{d} /$, or /Id/, depending on the final phoneme of the present tense stem, but a minority of verbs, such as catch, hit, and go, use alternative irregular past tenses. The issue that has animated psychologists involves the nature of the cognitive system underpinning the linguistic one, with different views as to the separability of the regular and the irregular processes (e.g., McClelland \& Patterson, 2002; Pinker \& Ullman, 2002).

In this paper, we will address a more subtle but surprisingly complex linguistic system: alternation in pronunciation of the definite article in English. Alternation of the indefinite article-realized as "a" or "an," depending on the following phoneme-is widely appreciated by English speakers, because it influences the spelling of the word, as well as the pronunciation. Less transparently, the indefinite article "the" has a similar allomorphic alternation, depending on whether it is followed by a consonant ("thuh,"

We thank Ardi Roelofs and Maggie Snowling for valuable discussions of this research, Philip Quinlan for statistical advice, and William Raymond and an anonymous reviewer for comments on an earlier draft of this paper. Correspondence concerning this article should be addressed to M. G. Gaskell, Department of Psychology, University of York, York YO10 5DD, England (e-mail: g.gaskell@ psych.york.ac.uk). /ðə/) or a vowel ("thee," /ði/). Variations can also be used for emphasis (e.g., "this isn't any old department, this is the department") and to signal speech production problems (Fox Tree \& Clark, 1997). Other function words also vary in terms of the likelihood of reduction as a function of the following segment, but to a lesser extent. Jurafsky, Bell, Fosler-Lussier, Girand, and Raymond (1998) found that "the" was 14 times more likely to contain a full vowel (i.e., "thee") if it was followed by a vowel than if it was followed by a consonant. The closest equivalent ratios for other words are 9 for "a," 4 for "to," and 1.7 for "of." Thus, article alternation is, to some extent, part of a more general reduction process, which can be affected by the following segment and by many other factors. Nonetheless, definite and indefinite articles show a much stronger influence of consonantal context, possibly because of the crystallization of the indefinite alternation in the orthography.

The selection of an article alternant might seem a trivial matter: The default behavior, on statistical grounds, would be production of the reduced form /ठə/, which would be overridden by a single unreduced exception form, /ði/, in the case of an upcoming vowel or a dysfluency or for emphasis. However, there appear to be differences between dialects and age groups in terms of the prevalence of unreduced forms preceding vowels. Keating, Byrd, Fleming, and Todaka (1994; see also Todaka, 1992) analyzed the TIMIT corpus, which contains recordings of sentences read by a wide range of speakers of American English. Despite the fact that the speech in TIMIT is not spontaneous, pronunciation of "the" varied widely, with more than just the identity of the following phoneme being influential. Todaka (1992) showed that the prevalence of /ði/ before 
vowels varied between dialects, with only $50 \%$ prevalence for the New York City dialect, as compared with more than $80 \%$ for New England, Western, and North Midland dialects. There was also a clear effect of age on use of /ði/ before vowels, with $63 \%$ prevalence for people in their 20 s, increasing to $100 \%$ for those over 50 . Further evidence for contextual influences on article allomorphy, using a corpus of spontaneous speech, was found by Bell, Jurafsky, Fosler-Lussier, Girand, and Gildea (1999). Their corpus (Switchboard; Godfrey, Holliman, \& McDaniel, 1992) was notable in that it contained fully 33 different phonological forms of the definite article.

Raymond, Fisher, and Healy (2002) examined the factors influencing definite and indefinite article production in American English, using an empirical, rather than a corpus-based, approach. Their study used both comprehension and production tasks to examine speaker preferences for a range of different following words. One experiment required participants to replace "his" in a spoken two-word phrase with "a/an" or "the." For example, the participant might hear "his government" and respond by saying "the government." This methodology allowed the experimenters to select particular words without presenting their written form, in order to examine whether they affected article choice. Two further experiments addressed the same issue by asking participants to select their preferred form given spoken versions of both alternants for a particular word pair (e.g., "thuh government" vs. "thee government"). For the purposes of this paper, we will focus on the results for the definite article, which showed much stronger effects of the following word. A consistent finding was that deviations from the normative rule ("thuh" before consonants and "thee" before vowels) were surprisingly common, particularly in the vowel case. For example, in the production experiment, $14 \%$ of the responses before consonant-initial words and $42 \%$ of the responses before vowel-initial words did not fit the normative rule. In the perception experiments, there was also an interaction between initial phoneme type (consonant vs. vowel) and lexical stress (first vs. second syllable). Vowel-initial words with first-syllable stress (e.g., attitude) and consonant-initial words with second-syllable stress (e.g., society) provoked more deviations from the normative rule than did vowel-initial words with secondsyllable stress (e.g., attention) and consonant-initial words with first-syllable stress (e.g., service). Perhaps most intriguing of all, Raymond et al. found that, in some cases, aspects of the spelling of the words following the article influenced its pronunciation. Specifically, words beginning with the consonant phoneme / $\mathrm{j} /$ provoked more deviations from the normative rule when they began with a vowel letter (e.g., united) than when they began with a consonant letter (e.g., yellow). This effect was significant in the two perception experiments and was marginally significant in the production experiment and suggests that, to some extent, whether or not a word is spelled with a vowel determines the selection of definite article form.

These results are striking because they suggest that the mechanism responsible for the selection of an article al- ternant is sensitive to far more than just the initial class of the following phoneme. Raymond et al. (2002) argued that the high level of deviation from the normative rule in performance implied that the underlying mechanism was not rule governed in the traditional sense. Instead, it seems that multiple constraints are active, including information about word stress patterns and orthographic factors. This alternative description of performance is compatible with a number of different models, such as probabilistic or variable rule models (Labov, 1969), analogical models (Serwatka \& Healy, 1998), and connectionist networks (Hare \& Elman, 1995).

However, Raymond et al.'s (2002) study left unanswered some questions about the mechanisms involved. The tasks used by Raymond et al. were rather unusual, in that they required either an explicit choice between two given alternatives or replacement of "his" with "the" in a simple two-word production task. The explicit nature of this task may have two effects on performance. There may be an inappropriate internal focus of attention on a normally automatic and unconscious process, which could increase error rates and lead to abnormal responses (cf. Wulf, McNevin, \& Shea, 2001). More worryingly, participants would most likely be able to identify the goal of the study quite quickly and may begin to respond using explicit knowledge of pronunciation "rules" or even some ad hoc principles generated by their observing their own responses. Explicit knowledge of regularities often lags behind implicit knowledge (e.g., Mathews et al., 1989; Reber, 1997), which may be part of the explanation for the high level of deviation from the normative rule for some conditions in Raymond et al.'s study. Explicit knowledge may be particularly relevant to the explanation of the orthographic effects shown in their study. If participants are making use of the (correct) explicit rule "say thuh before a consonant and thee before a vowel," they may be incorrectly influenced by spelling in their classification of the initial phonemes of the following words. That is, participants might be more likely to classify united as beginning with a vowel than yellow, because it is spelled with a vowel. People learn to classify letters as vowels and consonants when they learn to read, and although there is also awareness of the vowel-consonant distinction in terms of phonemes, people will be less able to classify particular phonemes (e.g., /j/) in this way. Orthographic influences in phoneme classification have been observed in phoneme monitoring and gating experiments (e.g., Dijkstra, Roelofs, \& Fieuws, 1995; Hallé, Chéreau, \& Segui, 2000), although in these cases the orthographic influence is not necessarily through explicit knowledge.

In Experiment 1, we replicated the speech production experiment of Raymond et al. (2002) but added a condition intended to address production performance when participants were unaware of the intention of the experiment. In this condition, instead of being given a stimulus phrase, such as "his yellow," with the explicit instruction to replace "his" with "the," the participants heard a pair of words, such as yellow and chick, and were asked to form a simple sentence combining those words (e.g., "the yel- 
low chick was fluffy"). This methodology did not guarantee that the participants would prefix the target word with the definite article, but it did make the goal of the experiment obscure to the participant.

In Experiment 2, we again addressed implicit selection of definite article allomorphs, but this time by looking at the development of the selection process, using groups of children between 7 and 10 years of age. So far as we know, ours is the first study to look at developmental trends in article alternant preference. Keating et al.'s (1994) study showed an intriguing correlation between unreduced /ði/ usage and age group for speakers ranging from 20 years in age and upward. However, the range of ages involved meant that the change could be seen either in terms of changes in performance over the lifetime of the speaker or in terms a change in the language itself from generation to generation. Keating et al. referred to the effect as "an ongoing change in a pronunciation norm" (Keating et al., 1994, pp. 136-137), whereas Raymond et al. (2002) were more equivocal. Language change normally occurs slowly, over the course of generations, whereas developmental changes tend to be swifter. The children in our study were all taught at the same school and were likely to have had very similar language environments. Therefore, if we find a substantial age effect on their alternant selection, we can be confident that it is a developmental change. Experiment 2 also provided an opportunity to examine at what point in development orthography begins to influence alternant selection.

\section{EXPERIMENT 1}

\section{Method}

Participants. Twenty-five male and 25 female undergraduate students at the University of York participated in the experiment. Their ages ranged from 18 to 22 years, with a mean age of 21.1 years. All the participants had British English as their first language.

Design and Materials. Two subtests were carried out using the same target materials (i.e., the words intended to follow "the"). The determiner replacement subtest was a straightforward replication of Experiment 1 of Raymond et al. (2002), in which participants heard "his" followed by a target word and had to say "the" and the target word. The other subtest was the sentence production task outlined above. All the participants completed the sentence production task before the determiner replacement task to ensure that, if they realized the object of the experiment during the replacement phase, this would not affect performance on sentence production, which was aimed at providing a pure measure of implicit knowledge.

The target words were taken largely from Raymond et al. (2002). These consisted of 72 words designed to investigate three factors balanced in a $2 \times 2 \times 2$ design, plus 54 words specially selected for specific comparisons (see Appendix A). The three factors manipulated in the main item set were initial phoneme class (vowel vs. consonant), lexical stress pattern (first- vs. second-syl lable stress), and word frequency (high vs. low). The remaining word sets allowed four further comparisons: (1) orthographic influence for $/ \mathrm{j} /$-initial words (e.g., united vs. yellow), (2) orthographic influence for vowel-initial words (silent "h" words [e.g., honor] vs. ordinary vowel-initial words), (3) first- versus second-syllable stress for "h"-initial words (e.g., hospital vs. heroic), and (4) initial vowel quality (the high front vowels / i/ [e.g., evening] and /I/ [e.g., influence] vs. other vowels [e.g., attitude]). The significance of comparison s (3) and (4) will be explained in the Results section. Each cell of the design contained 9 words, although in some cases, the special categories were compared with a larger set of items from the main item set. Within the main set of 72 items, words beginning with initial glides and liquids $(/ \mathrm{w} /, / \mathrm{j} /$, $/ \mathrm{r} /$, or $/ \mathrm{l} /$ ) were avoided for ease of variant form identification, and vowel-initial words began with vowels other than high or semi-high front vowels. Frequencies were determined using the norms of Kučera and Francis (1967). As in Raymond et al.'s study, highfrequency words were limited to those with per million frequencies above 100, as compared with between 1 and 10 for low-frequency items. The special words were not controlled for frequency, and only the initial " $h$ " words in comparison (3) were explicitly controlled for stress pattern.

The target words were paired with other words for the sentence production task. These words were selected with the intention of maximizing the likelihood of production of the definite article before the target word but were otherwise unconstrained. Twenty-six of the target words from Raymond et al. (2002) were unlikely to be preceded by "the" in this type of task and were replaced for both subtests by more suitable words with equivalent critical properties. For example, the word opulent from the original study was changed to otter, since it was considered unlikely that a participant would produce a sentence encompassing the phrase "the opulent." Twentysix filler trials were also used in the sentence production block, with word pairs selected to try to widen the range of plausible sentence structures used by the participants. The stimuli were recorded onto a $\mathrm{CD}$ in a soundproof booth by one of the co-authors and then were transferred digitally to PC. Individual word files (for the sentence production subtest) and two-word phrase files (for the determiner replacement subtest) were then created using Cool Edit software. The order of trials was randomized for each subtest and each participant in nine blocks, to ensure homogeneity of conditions.

Procedure. The participants were tested individually in a quiet room. The stimuli were delivered through Sennheiser HD265 Headphones, using DMDX software (Forster \& Forster, 2003) on a PC, and the participants' spoken responses were recorded digitally, using a microphone connected to the computer.

For the first (sentence production) subtest, the participants were given written instructions that they would hear two words and that they would have about $10 \mathrm{sec}$ in which to construct a short sentence including those words. A pilot study indicated that in order to encourage the participants to give the desired response (the use of "the" before the target word), it was necessary to make the instructions fairly specific. The participants were instructed that the sentence should be as simple as possible, should use the words in the given order, and should not be about themselves. They were asked not to alter the words in any way-for example, by adding "ing" or "s."

The sentence production subtest began with the presentation of six practice items, followed by nine blocks of test items. Short breaks were given after the third and sixth blocks. Each trial consisted of the presentation of the two spoken words, followed by a 7.5-sec delay and a tone to indicate that the participant should say the sentence. The participant had $5 \mathrm{sec}$ in which to respond, after which the next trial began.

After the sentence production test, the participants took a break and then were given written instructions that they would hear word pairs and that they should replace the first word ("his") with "the." The overall structure of the test followed that of the sentence production test, but with a different randomization within and between blocks. On each trial, the participant heard the target, preceded by "his" and followed by a tone $1.5 \mathrm{sec}$ later, signaling that the participant should say the response. After $3 \mathrm{sec}$, the next trial began.

Participant responses in both subtests were coded as correct or in error according to criteria based on the normative rule for definite article pronunciation. Thus, /ði/ responses were coded as correct before vowel-initial words but as incorrect before consonantinitial words, whereas /ðə/ responses were coded as correct before 
Table 1

Percentages of Deviations From the Normative Rule for Pronunciation of the Definite Article in Experiment 1

\begin{tabular}{lccccc}
\hline & \multicolumn{2}{c}{$\begin{array}{c}\text { Sentence } \\
\text { Production }\end{array}$} & & \multicolumn{2}{c}{$\begin{array}{c}\text { Determiner } \\
\text { Replacement }\end{array}$} \\
\cline { 2 - 3 } \cline { 6 - 7 } Condition & Low F & High F & & Low F & High F \\
\hline Consonant initial & & & & & \\
$\quad$ First-syllable stress & 0.3 & 1.4 & & 10.0 & 10.6 \\
Second-syllable stress & 0.7 & 1.8 & & 12.3 & 14.6 \\
Vowel initial & & & & & \\
First-syllable stress & 9.2 & 5.1 & & 17.6 & 16.2 \\
Second-syllable stress & 2.6 & 2.3 & & 10.2 & 12.3 \\
\hline
\end{tabular}

Note-F, frequency.

consonant-initial words but as incorrect before vowel-initial words. Two experimenters coded each response individually during the experiment, and in the rare cases in which there was a disagreement over responses, three experimenters examined the response waveform in order to reach a decision. As was mentioned in the introduction, the production of the definite article is likely to be partly influenced by a general reduction process, which may operate continuously, rather than dichotomously. Thus, the categorization of these tokens as either unreduced or reduced is likely to be somewhat artificial. Nonetheless, categorical decisions remain useful and valid as a measure of the extent of a continuous reduction process. We will return to this issue in the General Discussion section.

\section{Results and Discussion}

The responses for the determiner replacement subtest almost all contained one or the other allomorph of "the" $(99.6 \%)$, whereas only $60 \%$ of the responses in the sentence production experiment used the definite article immediately before the target word. There were many possible reasons for differences between different stimulus items in terms of usage of "the" (most particularly, how well the chosen word pair invited the desired sentence construction). Of interest here, however, is which of the two alternants was chosen when the definite article was used. Therefore, all the analyses will be based on the percentage of "the" responses deviating from the normative rule (see Table 1). Deviations from the normative rule will sometimes be abbreviated as errors.

A four-way analysis of variance (ANOVA) was carried out on the main set of 72 stimuli, using the variables of subtest (sentence production vs. determiner replacement), stress (first vs. second syllable), frequency (high vs. low), and initial phoneme (vowel vs. consonant). There was a main effect of subtest $\left[F_{1}(1,47)=30.2, p<.001\right.$; $\left.F_{2}(1,64)=299.8, p<.001\right]$, with more deviations from the normative rule for the determiner replacement condition $(13.0 \%)$ than for the sentence production condition $(2.9 \%)$. Therefore, the slightly artificial nature of the replacement subtest resulted in more errors. We asked the participants after the complete experiment for their views on what was being tested, and roughly half believed that the replacement subtest was analyzing their pronunciation of "the," whereas none of the participants thought that the sentence production task was related to pronunciation of "the." Therefore, it is possible that one cause of the inflated error rate in the replacement subtest was that the participants were devoting an abnormal level of attention to the alternation process. However, none of the other factors interacted with subtest, implying that any effects found were equivalent for both methodologies.

There was a main effect of stress $\left[F_{1}(1,47)=4.9, p<\right.$ $\left..05 ; F_{2}(1,64)=4.8, p<.05\right]$, plus an interaction between stress and initial phoneme $\left[F_{1}(1,47)=19.8, p<.001\right.$; $\left.F_{2}(1,64)=22.3, p<.001\right]$. As in Raymond et al.'s (2002) study, vowel-initial words with first-syllable stress (e.g., attitude; $12.0 \%$ ) and consonant-initial words with secondsyllable stress (e.g., society; $7.3 \%$ ) provoked more deviations from the normative rule than did vowel-initial words with second-syllable stress (e.g., attention; 6.9\%) and consonant-initialwords with first-syllable stress (e.g., service; $5.6 \%$ ). Perhaps the simplest way of understanding this interaction is in terms of first-syllable stress producing a bias toward a reduced "the" and second-syllable stress producing a bias in the opposite direction. Article alternant selection appears to be operating in accordance with an overall preference for alternating stress patterns, which is generally the case for English (e.g., Selkirk, 1984).

No other main effects or interactions were significant by both items and participants, although the interaction between initial phoneme and frequency was significant by participants $\left[F_{1}(1,47)=5.4, p<.05 ; F_{2}(1,64)=1.2, p>.1\right]$, and the main effect of initial phoneme was significant by items $\left[F_{1}(1,47)=1.4, p>.1 ; F_{2}(1,64)=28.1, p<.001\right]$.

The six other conditions were analyzed in two-way ANOVAs with experiment and condition as factors (see Table 2). For the 18 words beginning with $/ \mathrm{j} /$, there was a main effect of spelling $\left[F_{1}(1,49)=75.5, p<.001\right.$; $\left.F_{2}(1,16)=5.1, p<.05\right]$, with words beginning with vowel letters producing far more errors $(42.1 \%)$ than did consonant-initial words (19.9\%). Therefore, the participants were more likely to treat the $/ \mathrm{j} /$ as a vowel in terms of article alternant selection if it began with a vowel letter. Even if the word began with a consonant letter, the error rate was much higher for $/ \mathrm{j}$ /-initial words than for obstruent-

Table 2

Percentages of Deviations From the Normative Rule for the Selected Categories in Experiment 1

\begin{tabular}{|c|c|c|c|c|c|c|}
\hline & \multicolumn{2}{|c|}{$/ \mathrm{j} /$ words } & \multirow[b]{3}{*}{ Silent "h" } & \multirow{2}{*}{\multicolumn{2}{|c|}{$/ \mathrm{h} /$ words }} & \multirow[b]{3}{*}{ High Vowe } \\
\hline & \multirow{2}{*}{$\begin{array}{l}\text { Vowel } \\
\text { Letters }\end{array}$} & \multirow{2}{*}{$\begin{array}{c}\text { Consonant } \\
\text { Letters }\end{array}$} & & & & \\
\hline & & & & Syllable 1 & Syllable 2 & \\
\hline Determiner replacement & 40.2 & 23.6 & 18.1 & 10.7 & 21.3 & 21.4 \\
\hline Sentence production & 43.9 & 16.2 & 7.3 & 1.4 & 10.0 & 8.8 \\
\hline
\end{tabular}


initial words generally (6.4\%). This baseline difference suggests that the influence of initial segment type on alternant selection may not be dichotomous. Instead, the data fit a model in which degree of closure is a continuous variable acting probabilistically, so that glides such as $/ \mathrm{j} /$ fall between the extremes of obstruents and vowels, closer to the consonant end (cf. Jakobson, Fant, \& Halle, 1952).

The manipulation of subtest was intended to assess whether any effects of orthography relied on explicit knowledge of rules of alternation. There was no main effect of subtest in the analysis of $/ \mathrm{j} /$-initial words, but subtest did interact with spelling $\left[F_{1}(1,49)=5.3, p<.05\right.$; $\left.F_{2}(1,16)=5.1, p<.05\right]$. This interaction showed that far from eliminating the effect of spelling, the sentence production task actually amplified its effect. For determiner replacement, words beginning with a vowel letter produced $40.2 \%$ errors, as compared with $23.6 \%$ for consonant letter words, whereas in the sentence production subtest the error rates were $43.9 \%$ for vowel letters and $16.2 \%$ for consonant letters. These results are strong evidence for an implicit locus of orthographic effects in article alternant selection.

In a second analysis, we examined whether a silent " $h$ " in a vowel-initial word would influence pronunciation of the definite article. The set of nine words with a silent " $h$ " was compared with the 36 items from the main set beginning with a vowel. This comparison showed a main effect of subtest $\left[F_{1}(1,48)=14.2, p<.001 ; F_{2}(1,43)=88.1\right.$, $p<.001$ ], with fewer errors in sentence production $(6.0 \%)$ than in determiner replacement $(16.6 \%)$. However, there was no effect of spelling on error rate and no interaction between spelling and subtest. Raymond et al. (2002) also found little evidence for an influence of orthography for vowel-initial words, and given the very strong effect for consonant-initial words, it is unclear why. One possibility is that the use of the $/ \mathrm{j} /$ consonant placed the system in a region of high uncertainty, in which weaker constraints, such as spelling, could have strong effects.

For " $h$ "-initial words in which the " $h$ " is not silent, we tested whether stress assignment affected pronunciation of the definite article. The reason for this test was that, for indefinite articles, "h"-initial words with second-syllable stress are an accepted (although not universally agreed upon) exception. For example, historical is sometimes combined with an rather than with $a$. No such exception exists for the definite article, but some generalization is possible if the same system controls both definite and indefinite article alternant selection. Alternatively, the factors that have contributed to the development of the exception for indefinite articles (i.e., some lenition, or weakening, of the $/ \mathrm{h} / \mathrm{in}$ an unstressed syllable) may also operate in a less overt way for definite articles. For these stimuli, we found that there was the usual effect of subtest $\left[F_{1}(1,49)=14.1, p<.001 ; F_{2}(1,16)=60.1, p<.001\right]$, with more errors for determiner replacement, plus a main effect of stress assignment $\left[F_{1}(1,49)=39.5, p<.001\right.$; $\left.F_{2}(1,16)=24.2, p<.001\right]$, with more errors for secondsyllable stress (15.6\%) than for first-syllable stress $(6.1 \%)$, and no interaction. This effect of stress appears to be far bigger than the main effect of stress for the main set of items. Looking at the sentence production experiment, which we believe gives the best indication of the effects in normal language production, the " $h$ "-initial second-syllable stress items generated $10 \%$ deviations from the normative rule, as compared with $1.4 \%$ for "h"-initial words with firstsyllable stress. For obstruent-initial words with secondsyllable stress, the error rate was $1.2 \%$. Therefore, stress allocation appears to be particularly influential in the case of " $h$ "-initial words, which reinforces the conclusion that a tendency to treat words such as historical as exceptions for the indefinite article also holds true for definite article pronunciation. Again, the lack of interaction with subtest suggests that this effect is not based on faulty explicit rule formation.

Finally, a set of nine items with high front vowels (/i/ and /I/) was compared with the 36 vowel-initial words from the main set. These high front vowels are the closest to the vowel used in the unreduced form of "the," which is normally used before vowels. This similarity may have one of two consequences. There may be an assimilation process that further decreases the likelihood of a reduced "the" being produced. Alternatively, the presence of the following high front vowel may provide a bias toward a reduced "the" in order to increase comprehensibility and aid word segmentation. The data for this comparison supported the second alternative. There was a main effect of vowel type $\left[F_{1}(1,49)=13.5, p<.001 ; F_{2}(1,43)=8.1\right.$, $p<.01]$, with more deviations from the normative rule (i.e., reduced forms) for the high front vowels $(15.1 \%)$ than for the other vowels $(9.9 \%)$. There was also the expected main effect of subtest $\left[F_{1}(1,48)=17.1, p<.001\right.$; $\left.F_{2}(1,43)=88.3, p<.001\right]$ and no interaction.

As well as looking at the overall influence of the independent variables on performance in the two subtests, we also looked at whether, for any particular target word, the participants tended to provide the same allomorph in each of the subtests. To do this, we examined the frequency of the four different combinations of trial outcomes for the two subtests (ignoring trials in which the participant did not say "the" in one or the other subtest). On average, a participant in Experiment 1 made a response that fitted the normative rule in both subtests $77.2 \%$ of the time. Deviations in the determiner replacement, but not in the sentence production, subtest accounted for $14.4 \%$ of the trials, whereas deviations in sentence production, but not determiner replacement, accounted for $5.3 \%$ of the responses. Finally, on $3.1 \%$ of the trials, there was a consistent deviation from the normative rule in both subtests. Thus, $20 \%$ of the items were treated inconsistently, and deviations from the normative rule in the sentence production test were more often than not treated as fitting the normative rule in the determiner replacement test. Interestingly, there was the greatest level of inconsistency in the condition with the greatest number of deviations from the normative rule $(/ \mathrm{j} /$-initial words beginning with a vowel letter), for which $53 \%$ of the responses were inconsistent. This shows that the uncertainty created by some 
conditions of definite article selection is not dealt with consistently on a word-by-word basis, which might be expected if allomorph preference was lexically specified for each target word. Nonetheless, there is slightly more consistency overall than would be expected purely by chance. We tested this by estimating the number of trials of each type for each participant, assuming independence of performance in the two subtests. This gave an expected breakdown of $75.9 \%$ (normative rule in both), $15.7 \%$ (deviation in determiner replacement only), $6.6 \%$ (deviation in sentence production only), and $1.8 \%$ (deviation in both). The prevalence of deviations from the normative rule in both subtests (3.1\%) was outside the $95 \%$ confidence interval for this outcome, on the basis of the assumption of independence $(1.1 \%-2.4 \%)$.

In summary, Experiment 1 demonstrated an extensive array of factors that influence the selection of definite article alternants. Unsurprisingly, the most critical factor is whether or not the initial phoneme of the following word is a vowel, which predominates in the choice between the two forms of "the." However, our results support Raymond et al. (2002) in also demonstrating effects of lexical stress assignment (particularly for " $h$ "-initial words) and of the initial letter of $/ \mathrm{j} /$-initial words, as well as differential effects within both consonant and vowel classes. These factors have weaker effects on selection, but in certain combinations can form strong constraints in opposition to the normative rule.

With one exception, these effects did not interact with subtest type. Even when participants are producing sentences in relatively normal circumstances with no explicit knowledge of what aspects of their speech are under test, the same factors are operating. In fact, the only interaction with subtest, for the $/ \mathrm{j} /$-initial words, showed stronger effects of orthography for the more implicit task. These data, in combination, imply that the identified factors operate at a subconscious implicit level in normal speech production. This finding is most critical for evaluating the effect of orthography, since it implies that there is a rather subtle influence of orthographic representations on variant selection in speech production. We will return to this issue in the General Discussion section.

Our results do not support the results of Raymond et al. (2002) in one respect. One of the arguments they used against a rule-based model of article alternant selection was the high overall level of deviation from the normative rule (e.g., in their Experiment 3, they found an overall error rate of $21 \%$ ). The argument was that a normative rule model should permit only a relatively small proportion of errors (an acceptable error rate was viewed as up to around $8 \%$ ). Our results suggest that the overall error rate in their experiments was inflated by the choice of task, supporting the idea that the unusual focus of attention on what was largely an automatic process had impaired performance. We found an overall error rate of $13 \%$ for the main set of words tested when determiner replacement was used, but when we used a sentence production task, the error rate dropped to less than 3\%. Applying the $8 \%$ acceptable error rate principle to our participants in the sentence production task would lead to the conclusion that the vast majority (45 out of 50) was making use of a normative rule. As we have shown, however, these same participants were being influenced by far more than merely whether the following phoneme was a vowel or a consonant. Therefore, it seems that the true picture is one in which there is relatively little noise in the system (responses are generally governed by the dominant factor of the initial phoneme of the following word) but, nonetheless, multiple weak constraints operate in the selection of the form of the definite article.

\section{EXPERIMENT 2}

In Experiment 2, we addressed the developmental profile of the effects identified in Experiment 1. Two groups of children were tested on their use of variants of the definite article in a variety of sentence contexts. We had two aims in this study. We wished to examine whether there was any evidence for a developmentaldefault in operation early on in language acquisition. For example, given that there are more consonant-initial than vowel-initial words in the language, the language learner may reach a stage early on in development at which "the" is always used in its most common reduced form. Increased exposure to connected speech would then result in a gradual increase in complexity of the selection system, to accommodate the factors that are understood to apply in adulthood. This behavior would be consistent with the phenomenon of early overregularization found in other linguistic systems in development (e.g., Bybee \& Slobin, 1982; Maratsos, 2000; Marcus et al., 1992) and would shed light on the link between age and use of /ðə/ before vowels observed by Keating et al. (1994).

A second aim was to examine the influences during development of some of the factors identified in Experiment 1 . Although many phonologicalalternations become apparent in preschool years, there is some evidence that more subtle influences develop over a longer time course and even into adulthood (Guy \& Boyd, 1990). In the case examined here, we wished to find out whether orthographic influences could be observed at an age at which spelling rules are emerging and links between orthographic and phonological units are being forged. For this reason, we employed a reduced set of target words that focused on potential orthographic influences on article selection.

\section{Method}

Participants. Forty children were tested, with 20 (10 males, 10 females) in each age group. The children in the Year 3 group were between 7 years 7 months and 8 years 6 months of age, with a mean age of 7 years 11 months. The children in the Year 5 group were between 9 years 7 months and 10 years 6 months of age, with a mean age of 10 years 2 months. All were pupils at the same school in the West Midlands of England and were selected at random from the class. Thirty different children (15 from each age group) took part in a word familiarity test. All the children were native speakers of British English.

Design and Materials. The target stimuli for Experiment 2 consisted of six sets of 10 words (see Appendix B). These sets focused on the effects of following phoneme class on article selection and the effects of orthography. Two sets of words provided the vowel and 
consonant baselines for comparison with other sets and allowed examination of whether default behavior changed during development. Two further sets began with the $/ \mathrm{j} /$ phoneme, with one set comprising words beginning with consonant letters and the other containing vowel-letter-initial words. A further 10 items contained a silent "h," for comparison with the ordinary vowel-initial words. Finally, 10 items began with an "h" that was pronounced, for comparison with the normal consonant condition. As far as was possible, the words were selected to be familiar to young children, but in some cases (particularly the silent-" $h$ " and $/ \mathrm{j}$ / words beginning with vowel letters), there was a small pool of words to select from. Because of this, some of the words were low-frequency items, and the groups were matched item by item on Celex frequency (Baayen, Piepenbrock, \& van Rijn, 1993). ${ }^{1}$

Our intention was again to examine performance in a task for which the participant has no awareness of the object of the study. This was made easier by the fact that children generally have less awareness of linguistic alternations. The task chosen was similar to the sentence production task in Experiment 1 but was simplified to make it suitable for children as young as 7. It involved presenting the participants with a typed sentence frame containing a gap (e.g., "John put on the jumper"). This frame contained the entire sentence the participant was required to produce, apart from the target word. The target word was then presented orally, to avoid inducing orthographic effects through visual presentation. The participant was then required to produce the full sentence, with the target word filling the gap. The visual presentation of the sentence frame reduced memory load and also avoided any priming effect for the pronunciation of the definite article through spoken presentation. Sentence frames were simple and semantically and syntactically congruent with the target word. Only words assumed to be highly familiar to the children were used.

Procedure. The participants were tested individually in a quiet room. The procedure was explained to them, and they were given an opportunity to ask questions. In each trial, the child was presented with a typed sentence frame containing a missing word and were told the target word (e.g., "The word is yellow"). The participant was then encouraged to read the complete sentence fluently, with the target word being incorporated. If there were problems with pronunciation, the experimenter provided help without using the definite article. If there was a dysfluency, the child was encouraged to repeat the sentence, and the response was recorded for the fluent sentence.

Four practice sentences were used, followed by 60 test sentences, presented 4 per A4 page, with the order of the pages randomized for each participant. The experimenter recorded the pronunciation of the definite article before each target word as either reduced ("thuh," $/ ð ə /$ ) or unreduced ("thee," /ði/). Five out of 20 test sessions for each age group were recorded on audio tape and then recoded by an independent experimenter, with a high level of agreement.

A written familiarity test was given to different children from the same year groups (15 from each). This listed the target words from the main experiment, and the children were asked to mark the words they were familiar with.

\section{Results and Discussion}

In Experiment 1, we categorized responses in terms of whether they fitted the normative rule for definite article selection. Here, however, one of the research questions is whether or not an alternation exists between reduced and unreduced forms of "the" at the ages we are testing. Therefore, the responses in Experiment 2 were coded simply in terms of the percentage of "the" responses that took the unreduced form ("thee," /ði/). These figures, along with the target word familiarity ratings (expressed as the percentage of the participants who found the word familiar), are given in Table 3 .

Two sets of words contained normal vowel-initial and consonant-initialtarget words. The consonant-initialwords uniformly provoked selection of the reduced definite article (only 2 out of 400 responses were classed as unreduced). However, use of the unreduced article before vowel-initial words was not pervasive, as it had been for the adults. On average, $34 \%$ of these items were preceded by an unreduced "the" for the 8 -year-olds and $61 \%$ for the 10 -year-olds. The equivalent conditions in the sentence production condition of Experiment 1 showed 91\%-98\% usage of the unreduced form. An ANOVA on the children's data showed main effects of age $\left[F_{1}(1,38)=9.5\right.$, $\left.p<.01 ; F_{2}(1,18)=21.0, p<.001\right]$ and initial phoneme $\left[F_{1}(1,38)=120.4, p<.001 ; F_{2}(1,18)=237.7, p<.001\right]$, with a significant interaction between the two variables $\left[F_{1}(1,38)=9.2, p<.01 ; F_{2}(1,18)=19.5, p<.001\right]$. The data thus show a developmental trend of increasing usage of the unreduced definite article before vowels, with no change in behavior for consonant-initial words. Although we have sampled only two points in development cross-sectionally, the most parsimonious explanation for these results is that, early on in language development, the reduced form of "the" predominates in all circumstances. This is followed by a gradual increase in the use of the unreduced form before vowels, which becomes dominant at some point around age 10. The large shift in performance found here (a near doubling of the number of unreduced responses between the two age groups) seems impossible to explain in terms of differing language environments for the two groups.

We also looked at whether a target word's spelling would influence the alternant selection process. Despite the fact that target words were presented orally, there was an effect of spelling for $/ \mathrm{j}$ /-initial word, with more unreduced forms for words beginning with vowel letters than for words beginning with consonant letters $\left[F_{1}(1,38)=\right.$ $\left.18.8, p<.001 ; F_{2}(1,18)=5.0, p<.05\right]$. This effect appeared to be largely carried by the older participant group, although the effects of age $\left[F_{1}(1,38)=6.8, p<.05\right.$; $\left.F_{2}(1,18)=1.7, p>.1\right]$ and the interaction between age and initial letter $\left[F_{1}(1,38)=6.8, p<.05 ; F_{2}(1,18)=1.7\right.$, $p>.1]$ were significant only by participants.

Finally, we examined performance on words beginning with the letter "h." The vast majority of these words begin with the $/ \mathrm{h} /$ phoneme, but a few begin with a vowel. We looked at whether this inconsistency influenced pronunciation of the preceding definite article. A comparison between the pronounced-" $h$ " words and other consonant-

Table 3

Percentages of Use of the Unreduced Definite Article and of Target Word Familiarity (Fam) for Experiment 2

\begin{tabular}{|c|c|c|c|c|}
\hline \multirow[b]{3}{*}{ Condition } & \multicolumn{4}{|c|}{ Age Group } \\
\hline & \multicolumn{2}{|c|}{ Year 3} & \multicolumn{2}{|c|}{ Year 5} \\
\hline & Use & Fam & Use & Fam \\
\hline Consonant initial & 0.0 & 43 & 0.5 & 69 \\
\hline $\begin{array}{l}\text { Vowel initial } \\
\text { /j/ words }\end{array}$ & 34.0 & 41 & 60.5 & 76 \\
\hline Vowel letter & 1.5 & 31 & 6.0 & 67 \\
\hline Consonant letter & 0.0 & 57 & 0.0 & 77 \\
\hline$/ \mathrm{h} /$ initial & 0.0 & 56 & 1.0 & 81 \\
\hline Silent "h" & 37.5 & 44 & 62.5 & 65 \\
\hline
\end{tabular}


initial words showed no effects, suggesting that the inconsistency in pronunciation of these words did not influence variant selection. Similarly, a comparison between silent-"h" words and normal vowel-initial words showed an effect of age $\left[F_{1}(1,38)=7.9, p<.01 ; F_{2}(1,18)=32.2\right.$, $p<.001$ ] but no effect of spelling or interaction between age and spelling. The developmental data, therefore, match the adult data, showing an effect of orthography for /j/-initial words but no influence of a silent "h."

The ratings data collected at the same time suggested that target words varied widely in familiarity, with (unsurprisingly) higher familiarity ratings for the older age group. Our response collection procedure was designed to eliminate dysfluencies by asking the participants to repeat the sentence if a dysfluency was detected. However, there may be a more subtle effect of familiarity on production, which could influence performance. For example, it is possible that highly familiar words are more likely to be incorporated into the adult normative rule (although for the adult data, there were no reliable effects of frequency on performance). Therefore, we looked at whether there was any correlation between familiarity ratings and article alternation. Overall, there were no significant correlations between familiarity levels and production of the unreduced form (Year 3, $r=-.016, p>.1$; Year 5: $r=-.112$, $p>.1)$. As an additional check, we looked at the two subgroups of items that showed higher levels of unreduced definite articles: vowel-initial words and $/ \mathrm{j} /$-initial words. Again, no significant correlations were found (vowelinitial, Year 3, $r=.186, p>.1$; vowel-initial, Year 5, $r=$ $-.181, p>.1 ; / \mathrm{j} /$-initial, Year $3, r=-.352, p>.1 ; / \mathrm{j} /-$ initial, Year $5, r=-.359, p>.1$ ). Therefore, there is no evidence to suggest that familiarity with the words was affecting performance. This finding is important, because it implies that even for very low familiarity words, the alternation of the definite article operates normally. In a few cases, the selected words were effectively novel to the Year 3 group. For example, seven words, such as candelabra, harmonica, honorary, and odious, were rated as familiar by fewer than $10 \%$ of the Year 3 children. Nonetheless, these items were treated in the sentence production test in the same way as were other members of their class. Clearly, orthography can influence performance only if the following word's spelling is known (which may explain why the effects of orthography in the experiment were much smaller and were nonsignificant for the Year 3 participants), but the overall effect of following segment type on alternant selection does not appear to rely on familiarity with the following word itself. This is strong evidence against a model of alternant selection that relies on lexical information about the following word to operate. Like other linguistic systems, the selection of an article alternant can be generalized to relatively novel or unfamiliar items.

\section{GENERAL DISCUSSION}

The results of the two experiments here confirm the role of a range of different linguistic constraints on the pronunciation of the definite article in English. In Exper- iment 1, the most influential factor on pronunciation was the class of the initial phoneme of the following word, with the reduced form generally preceding a consonant and the unreduced form generally preceding a vowel. This alternation is widely recognized. However, other factors also influenced selection. Within the overall class of consonants, / $\mathrm{j}$-initial words were atypical in that they were more likely to be preceded by an unreduced "thee," and within the overall class of vowels, the high front vowels /i/ and $/ \mathrm{I} /$ were atypical in that they were more likely to be preceded by a reduced "thuh." There was also a weak preference for alternating stress patterns, with the selection of a reduced "thuh" more likely if the following syllable had primary lexical stress. This effect of stress was amplified in the case of $/ \mathrm{h} /$-initial words, mirroring the established exception to the normative rule for indefinite article production (e.g., "an historical"). The stress effect, in both cases, may be due to a lenition of the / $h$ / in unstressed syllables, leading to a more vowel-like quality, or may be thought of as a generalization of the exceptional case from indefinite to definite articles. The only difference would then be that the effect for indefinite articles has become crystallized in the orthography, whereas the effect for definite articles often remains unobserved by speaker and listener. Perhaps most surprising, both experiments showed an effect of the spelling of the following word on alternant selection. In Experiment 1, this was an influential factor for $/ \mathrm{j} /$-initial words, with an increase in the use of the unreduced form from $16 \%$ to $44 \%$ in the sentence production task. In Experiment 2, the increase for 8- to 10year-olds was much smaller but, nonetheless, significant.

The conditions in which factors such as stress assignment and orthography had the greatest influence were the ones in which the initial segment of the target word was, to some extent, intermediate between a consonant and a vowel. Thus, orthography was influential for words beginning with $/ \mathrm{j} /$, which as a glide is sometimes termed a semi-vowel and is standardly thought of as an intermediate segment (Jakobson et al., 1952). On the other hand, orthography had no effect for words beginning with standard vowels. Similarly, the influence of stress assignment was much stronger for $/ \mathrm{h} /$-initial words than for obstruent or vowel-initial words. Although often classified as a fricative, $/ \mathrm{h} /$ has also been classified as a glide (e.g., Jakobson et al., 1952), due to its vowel-like properties. This pattern of results suggests that factors such as stress assignment and spelling are secondary constraints on definite article selection and have a strong influence only when the initial phoneme of a word is not a typical vowel or consonant. Such a characterization predicts that words beginning with other glides, such as /w/, will be similarly treated in a variant way (cf. wand vs. once).

\section{Mechanisms of Alternant Selection}

The nature of the sentence production task in both experiments obscured the goal of the experiment to such an extent that we can now rule out one possible explanation of these effects. We argued in the introduction that the effects in Raymond et al. (2002) could be due partly to the 
misapplication of conscious rules extracted from observation of the language or to the participant's own performance in the test. The same cannot be said of the present results, meaning that the multiple constraints we have observed here operate implicitly during normal language production.

What kind of model, then, could support this alternation? Current models of speech production are not well specified in terms of the mechanisms underlying form variations, but they do provide a useful structure to which to refer. We will discuss the selection of article alternant with reference to the broad architectural distinctions of Levelt, Roelofs, and Meyer's (1999) model, which describes speech production as a succession of discrete stages, ranging from the lexical concepts to articulation of the speech itself. Within this model, some systematic variations in form occur at a relatively peripheral level. For example, Levelt et al. assumed that resyllabification of a sequence of words occurs at the phonetic-encoding level. As was mentioned, reduction of function word vowels is not restricted to the definite article, and it is quite possible that reduction is a continuous process. One mechanism that could account for some features of the present results might involve gestural overlap at this late stage of speech production (cf. Browman \& Goldstein, 1992). By this kind of account, the "intended" or lexical pronunciation of the definite article might always be the reduced form, but the overlap with the following segment will dictate to what extent the vowel is obscured and perceived as reduced. Consonants will tend to provide a more occluding context than will vowels, leading to differences in the perceived degree of reduction between consonant and vowel contexts.

Although the potential of this kind of mechanism to explain some of the variability between conditions of following context cannot be discounted, it seems implausible that the full range of effects can be explained in this way. First, a gestural overlap model would have great difficulty in explaining the alternation between "a" and "an" in the indefinite article case, because the final consonant of $/ \mathrm{n} /$ would tend not to be obscured by a following consonant. As the present results have demonstrated, there are strong similarities between the factors influencing definite and indefinite article alternations, suggesting some commonality in the locus of the effects. In addition, although vowel reduction before consonants occurs for other function words, such as "to" (Jurafsky et al., 1998), the influence of the following segment is much weaker, suggesting that the alternation cannot be fully explained in terms of simple gestural overlap. Furthermore, to our knowledge, there is no equivalent alternation in the case of final vowels of content words, as might be expected on a gestural overlap account (e.g., in British English the lazy in "lazy boy" would not be confused with laser).

An alternative is that the preferred pronunciation of the definite article is stored in the lexical representation for each potential following word. For example, in Levelt et al.'s (1999) model, the lemma level contains informa- tion about permissible syntactic roles and morphological variants for a word. The lemma level for content words could be extended quite simply to cover the preferred article form, along with information about similar variants. However, this lexical explanation would say nothing about how the preference for each potential following word is decided and stored and would also need an additional mechanism for the generalization to unfamiliar words in Experiment 2.

A lexical model would also assume that, within any speaker, the choice of article alternant should be consistent for any particular word. For example, if the lemma level for "unite" specifies an unreduced article in one individual's lexicon, that person should consistently say "thee united." The degree of consistency found between subtests in Experiment 1 was surprisingly low: Although $80 \%$ of the target words were attached to the same definite article allomorph in the two subtests, this may be largely because the normative rule is numerically very dominant. In the condition with the highest deviation from the normative rule $(/ \mathrm{j} /$-initial words beginning with a vowel letter), the majority of the target words $(53 \%)$ were treated inconsistently across the subtests. It is difficult to draw strong conclusions about consistency on the basis of such a small amount of data and given the difference between the two subtests in terms of task. Nonetheless, the substantial level of inconsistency in the participants' responses for some subgroups of words (particularly where the influence of orthography is strong) is not predicted by a lexical model.

A further possibility is a more dynamic process operating on the properties of the relevant words (their phonological, orthographic, and metrical representations), rather than reliance on stored knowledge. This process would allow generalization to novel words, would not necessarily produce a consistent selection for any particular word, and need not result in a categorical selection. In terms of Levelt et al.'s (1999) hierarchy, this process would have to occur at a stage at which all the relevant forms of information about the word following "the" were availablepossibly the phonological encoding stage. The definite article could be linked in a spreading-activation framework to two competing phonological forms, with the phonological forms also linked to the relevant properties of the following word: the initial phoneme, the initial letter, and the metrical frame. With appropriate weights in the links, multiple constraints on article variant selection could be accommodated, with, potentially, a continuum of response types, from fully unreduced to fully reduced.

Of course, such a model would still not explain why the production system behaves as it does. To address this issue, we need to consider the effects of learning on performance and also the interaction between perception and production (cf. Hare \& Elman, 1995). For the sake of argument, we can assume that the language learner receives as input a set of tokens of "the" embedded in connected speech and roughly conforming to the normative rule. Consonant-initial words are numerically dominant (a 
search of the Celex database for open class words showed a greater than 4:1 ratio by type and by token). Therefore, if we think of language learning as a progression through successive approximations to the input function, the first approximation should be to produce a reduced "the" in all circumstances. By extrapolation from the data in Experiment 2, this appears to be the case early on in life (perhaps until the age of 5). There then follows a period of adjustment, in which the main class of exceptions to this rule (vowel-initial words) is treated differently. Experiment 2 suggests that this adjustment is ongoing between the ages of 8 and 10, and Experiment 1 suggests that it is largely complete by university age in the population represented by our sample. ${ }^{2}$ There may well be further adjustment in later life (Keating et al., 1994).

As literacy develops, orthographic representations become available during the course of speech perception. These representations may influence the course of spoken word recognition (Ziegler \& Ferrand, 1998) and are clearly involved in speech production in the case of reading aloud. Although the correct encapsulation of the conditions required for an unreduced article involves the initial phoneme of the word, the correlation between initial phoneme and letter classes is very high. Of the 7,171 vowel-initial open class words in Celex, $22(0.3 \%)$ begin with a consonant letter. Similarly, 111 out of 32,372(0.3\%) consonant-initial open class words begin with a vowel letter. Therefore, the association of vowel-initial letters and unreduced definite articles will be strong, resulting in a tendency to produce the unreduced form before such words as united. The effect of stress on " $h$ "-initial words can be thought of in the same light. The circumstances in which the definite and the indefinite articles alternate are nearly identical, and so for the one case in which they differ, there is a tendency for definite article production to follow the pattern for indefinite article production.

It is possible that the universal effect of stress assignment on alternant selection can be thought of as a further generalization of the specific effect for " $h$ "-initial words. However, in terms of the statistics of the language, this proposal is unlikely, because " $h$ "-initial words make up a small proportion of the language as a whole. Instead, we attribute the small overall effect of lexical stress to a general preference for alternating stress found in many situations in English (cf. eurhythmy; Selkirk, 1984).

\section{Orthographic Influences in Speech Processing}

The major influence of phonology in adult reading, language development, and language disorders is widely recognized. In visual word recognition, the activation of a phonological representation plays an important role in the outcome of the recognition process (e.g., Lukatela \& Turvey, 1994; Van Orden, 1987), with some suggestion that reading involves access to a relatively unanalyzed, detailed representation of speech (Lukatela, Eaton, Lee, \& Turvey, 2001). Equally, reading development - both normal and disordered - has been linked to metaphonological abilities (e.g., Bruck, 1992; Goswami \& Bryant, 1990).
This close involvement of phonology in reading has led some authors to argue that interactive feedback links exist between phonological and orthographic representations (e.g., Stone, Vanhoy, \& Van Orden, 1997).

The flip side of this interaction is that there have been fewer demonstrations that orthographic knowledge influences speech production and perception processes. Most of those that have, both for adults and in development, have employed tasks that have a metaphonological component. For example, Bruck (1992) showed that the spelling of a word influenced performance in phoneme counting and deletion tasks for age groups similar to those used in Experiment 2. Children as young as 7 showed a strong influence of spelling when asked to count the phonemes in nonwords containing digraphs (e.g., a participant hearing the word "roof" might say there are four sounds, when only three phonemes are present). An equivalenteffect was found for phoneme deletion, although this effect was present only for children 8 years of age and above. Therefore, as in our experiments, orthographic influences are present quite early in reading development and appear to increase with age. In a similar vein, Treiman and Cassar (1997) showed that children 6-7 years of age and adults were influenced by spelling in a phoneme-counting task involving diphthongs.

These studies are informative about phonological knowledge, but by their nature, the tasks involved entail conscious reflective processing. If only certain levels of the phonological system are accessible to conscious awareness, it remains unknown whether these levels are involved in normal language processing and whether the deeper levels are affected by orthography in the same way (cf. Morais \& Kolinsky, 1994). Orthographic effects have also been shown in adults, using speeded tasks such as phoneme monitoring (Dijkstra et al., 1995; Hallé et al., 2000) and rhyme judgment (Seidenberg \& Tanenhaus, 1979), but once again there is the possibility that the representations made available in these tasks are not used in normal language processing. Perhaps the best evidence so far of an influence of spelling in word recognition is the study of Ziegler and Ferrand (1998), who found an effect of orthographic-phonological feedback consistency on the speed of lexical decision to spoken words. Our study has demonstrated that the role of spelling in speech production found by Raymond et al. (2002) is part of normal speech production and does not require reflective use of conscious rules (see also Damian \& Bowers, 2003). We have also shown that this orthographic effect, like the orthographic effects on metaphonologicaltasks, is evident in language development, as well as in adulthood. Our study does not imply that orthography shapes the phonological representations used in speech production, nor does it require feedback or interaction between orthographic and phonological representations, but it does demonstrate the involvement of spelling in a production process that might be thought of as purely phonological. The results suggest that the stage of processing at which the alternant of the definite article is selected has access to a variety of types of information, including the spelling of the following word. 


\section{Conclusions}

In sum, our research points to a wide range of factors that determine the selection of definite article allomorphs in speech production. It appears that, in English, the use of unreduced definite articles before vowels increases throughout childhood and possibly also throughout adulthood. Other factors become weakly influential-most notably, the status of the initial letter of the following word, which exerts an influence even under conditions in which the written word has not been presented and the speaker does not know that article selection is being monitored. These results suggest that models of speech production must allow allomorph selection to occur at a stage of processing in which a wide variety of local information is present and that this selection process must generalize to cases in which the following word is unfamiliar or even unknown.

\section{REFERENCES}

Ba ayen, R. H., Piepen brock, R., \& van Rijn, H. (1993). The CELEX lexical database [CD-ROM]. Philadelphia: University of Pennsylvania, Linguistic Data Consortium.

Bel 1, A., Jur af sky, D., Fosl er-Lu ssier, E., Gir and, C., \& Gil dea, D. (1999). Forms of English function words: Effects of disfluencies, turn position, age and sex, and predictability. In Proceedings of the XIVInternational Congress of Phonetic Sciences (pp. 395-398). Berkeley: University of California, Linguistics Department.

Browman, C. P., \& Gol dst ein, L. (1992). Articulatory phonology: An overview. Phonetica, 49, 155-180.

Bruck, M. (1992). Persistence of dyslexics' phonological awareness deficits. Developmental Psychology, 28, 874-886.

Bybee, J. \{L.\} (1995). Regular morphology and the lexicon. Language \& Cognitive Processes, 10, 425-455.

Bybee, J. L., \& Sl obin, D. I. (1982). Rules and schemas in the development and use of the English past tense. Language, 58, 265-289.

Damian, M. F., \& Bowers, J. S. (2003). Effects of orthography on speech production in a form preparation paradigm. Journal of Memory \& Language, 49, 119-132.

Dijkst ra, T., Roel ofs, A., \& Fieuws, S. (1995). Orthographic effects on phoneme monitoring. Canadian Journal of Experimental Psychology, 49, 264-271.

Forst er, K. I., \& For st er, J. C. (2003). DMDX: A Windows display program with millisecond accuracy. Behavior Research Methods, Instruments, \& Computers, 35, 116-224.

Fox Tr ee, J., \& Cl ark, H. (1997). Producing "the" as "thee" to signal problems in speaking. Cognition, 16, 151-167.

Godfrey, J., Holl iman, E., \& McDaniel, J. (1992). SWITCHBOARD: Telephone speech corpus for research and development. In IEEE International Conference on Acoustics, Speech, \& Signal Processing '92 (pp. 517-520). Piscataway, NJ: IEEE Press.

Goswa mi, U., \& Bryant, P. E. (1990). Phonologicalskills and learning to read. Hove, U.K.: Erlbaum.

Gu y, G., \& Boyd, S. (1990). The development of a morphological class. Language Variation \& Change, 2, 1-18.

Hall é, P. A., Chéreau, C., \& Segui, J. (2000). Where is the /b/ in "absurde" [apsyrd]? It is in French listeners' minds. Journal of Memory \& Language, 43, 618-639.

Hare, M., \& El man, J. L. (1995). Learning and morphological change. Cognition, 56, 61-98.

Ja kobson, R., Fant, G., \& Hall e, M. (1952). Preliminaries to speech analysis. Cambridge, MA: MIT Press.

Jur afsky, D., Bel 1, A., Fosl er-Lu ssier, E., Gir and, C., \& Raymond, W. (1998). Reduction of English function words in Switchboard. In R. H. Mannell \& J. Robert-Ribes (Eds.), Proceedings of the 5th International Conference on Spoken Language Processing (pp. 3111-3114). Sydney: Australian Speech Science and Technology Association.

Keat ing, P., Byrd, D., Fl eming, E., \& Todaka, Y. (1994). Phonetic analysis of the TIMIT corpus of American English. Speech Coтmunications, 14, 131-142.

Kü̈er a, H., \& Francis, W. N. (1967). Computational analysis of present-day American English. Providence, RI: Brown University Press.

Labov, W. (1969). Contraction, deletion, and inherent variability of the English copula. Language, 45, 715-762.

Level t, W. J. M., Roel of s, A., \& Meyer, A. S. (1999). A theory of lexical access in speech production. Behavioral \& Brain Sciences, 22, 1-38.

Lukat el a, G., Eat on, T., Lee, C., \& Turvey, M. T. (2001). Does visual word identification involve a sub-phonemic level? Cognition, 78, B41-B52.

Lukat el a, G., \& Tur vey, M. T. (1994). Visual lexical access is initially phonological:2. Evidence from phonological priming by homophones and pseudohomophones. Journal of Experimental Psychology: General, 123, 331-353.

Mar at sos, M. (2000). More overregularizations after all: New data and discussion on Marcus, Pinker, Ullman, Hollander, Rosen \& Xu. Journal of Child Language, 27, 183-212.

Mar cu s, G. F., Pin ker, S., Ul 1 man, M., Hol 1 ander, M., Rosen, T. J., $\& \mathrm{Xu}, \mathrm{F}$. (1992). Overregularization in language-acquisition. Monographs of the Society for Research in Child Development, 57, R5R165.

Mat hews, R. C., Buss, R. R., St anl ey, W. B., B1 anchard-Fiel ds, F., Cho, J. R., \& Druhan, B. (1989). Role of implicit and explicit processes in learning from examples: A synergistic effect. Journal of Experimental Psychology: Learning, Memory, \& Cognition, 15, 1083 1100 .

McCl el 1 and, J. L., \& Pat t er son, K. (2002). Rules or connections in past-tense inflections: What does the evidence rule out? Trends in Cognitive Sciences, 6, 465-472.

Mor ais, J., \& Kol insky, R. (1994). Perception and awareness in phonological processing: The case of the phoneme. Cognition, 50, 287-297.

Pinker, S., \& Ul 1 man, M. T. (2002). The past and future of the past tense. Trends in Cognitive Sciences, 6, 456-463.

Raymond, W. D., Fisher, J. A., \& Healy, A. F. (2002). Linguistic knowledge and language performance in English article variant preference. Language \& Cognitive Processes, 17, 613-662.

Reber, A. S. (1997). Implicit ruminations. Psychonomic Bulletin \& Review, 4, 49-55.

Seidenberg, M. S., \& Tanenhaus, M. K. (1979). Orthographic effects on rhyme monitoring. Journal of Experimental Psychology: Human Learning \& Memory, 5, 546-554.

Sel kirk, E. (1984). Phonologyand syntax: The relation between sound and structure. Cambridge, MA: MIT Press.

Ser wat ka, M., \& Healy, A. F. (1998). On the status of the count-mass distinction in the mental grammar. In A. F. Healy \& L. E. Bourne, Jr. (Eds.), Foreign language learning: Psycholinguistic studies on training and retention (pp. 113-158). Mahwah, NJ: Erlbaum.

St one, G. O., Vanhoy, M., \& Van Or den, G. C. (1997). Perception is a two-way street: Feedforward and feedback phonologyin visual word recognition. Journal of Memory \& Language, 36, 337-359.

Todaka, Y. (1992). Phonetic variants of the determiner "the." UCLA Working Papers in Phonetics, 81, 39-47.

Treiman, R., \& Cassar, M. (1997). Can children and adults focus on sound as opposed to spelling in a phoneme counting task? Developmental Psychology, 33, 771-780.

Van Orden, G. C. (1987). A ROWS is a ROSE: Spelling, sound, and reading. Memory \& Cognition, 15, 181-198.

Wulf, G., McNevin, N., \& Shea, C. H. (2001). The automaticity of complex motor skill learning as a function of attentional focus. Quarterly Journal of Experimental Psychology, 54A, 1143-1154.

Ziegl er, J. C., \& Fer r and, L. (1998). Orthography shapes the perception of speech: The consistency effect in auditory word recognition. Psychonomic Bulletin \& Review, 5, 683-689.

\section{NOTES}

1. The mean log frequencies for the six item sets were the following: consonant-initial, 0.91; vowel-initial, 1.09; "h"-initial, 1.18; silent-"h," 
$0.83 ; / \mathrm{j} /$-initial with consonant letter, $1.02 ;$ and /j/-initial with vowel letter, 0.90 . These conditions did not differ significantly $(F<1)$.

2. Although we can be reasonably confident that the two groups of children in Experiment 2 had similar language environments, the same cannot be said of the comparison between experiments. Therefore, it is quite possible that some of the differences between Experiments 1 and 2 in terms of alternant selection were due to language change or differences in language environment between the two groups of participants. Nonetheless, it seems unlikely that the children in Experiment 2 will not progress to an approximation of the normative rule by adulthood.

\section{APPENDIX A \\ Stimuli Used in Experiment 1}

The words are listed in pairs, with starred words being the target words in both subtests and the other member of each pair being used only in the sentence production subtest. The order within the pairs is the order of presentation used in the sentence production subtest.

\section{Consonant initial, first-syllable stress, high frequency}

government*_country; number*_unbelievable;program*_cliffhanger; service*_poor; public*_ toilets; special*_bargain; business*-crisis; problem*-immense; family*-park

Consonant initial, first-syllable stress, low frequency

bargain*-happy, detour*-inconvenient, banker*_late, facial*_radiant, potent*-smell, pastry*_ delicious, parrot*-cage, nuisance*-class, frantic*-screamed

\section{Consonant initial, second-syllable stress, high frequency}

particular*-person, president-society*, political*-controversial, position*-uncomfortable, member-committee*, direct*-cancelled, department*-psychology, production*-elaborate, condition*-poor

Consonant initial, second-syllable stress, low frequency

deranged*-irrationally, portrayal*_inaccurate, banana*-bruised, complexion*_girl, communal*_ mess, descendant*-unpopular, mirage*-desert, enjoyed-terrific*, disgusting*-overpowering

Vowel initial, first-syllable stress, high frequency

office*-cluttered, attitude*-woman, open*-draft, answer*-no, early*-worm, action*_film, area*-extensive, order*-wrong, worth-effort*

Vowel initial, first-syllable stress, low frequency

auction*-boring, artifact*-valuable, acrobat*-impressive, otter*-swimming, olive*_salty, octopus*-ugly, aging*-process, ulcer*-stomach, abdomen*-body

Vowel initial, second-syllable stress, high frequency

existence*_God, addition*-beneficial, analysis*-complicated, loved-experience*, enjoyedattention*, original*-version, expected*-result, example*-helpful, idea*-groundbreaking

Vowel initial, second-syllable stress, low frequency

excursion*-enjoyable, enlargement*-photograph, ornate*-antique, astute*-professor, omission*-disastrous, amoeba*-microscope, aroma*-tempting, abrasion*-arm, abnormal*growth

\section{/j/-initial words with initial vowel letter}

eucalyptus*-plant, united*-America, universe*-infinite, unit*-currency,

unicorn*-beautiful, eulogy*-moving, use*_drugs, uniform*-soldier, uterus*_baby

\section{/j/-initial words with initial consonant letter}

yearly*_event, yo-yo*_broken, yell*_deafening, yelp*_dog, yellow*-chick, yacht*_impressive, youth*-trouble, youngster*-lost, yogurt*-tasty

\section{Silent " $h$ " words}

honorable*-gentleman, hourly*-late, on-hour*, hourglass*-smashed, honor*-tremendous, heiress*-pretty, heirloom*-valuable, honesty*-judge, honest*-answer

Nonsilent " $h$ " words with first-syllable stress

hairy*_dog, hospital*-busy, dropped-hammer*, helmet*_hard, husband*-affair, healthy*_ option, hallway*-narrow, haggard*-witch, history*-England

Nonsilent " $h$ " words with second-syllablestress

hereditary*-fatal, humongous*_dog, heroic*-died, helpful*_assistant, hotel*-en-suite, humidity*-unbearable, ship-horizon*, horrendous*_exam, horrific*_ordeal.

\section{High front vowel-initial words}

insane*-hospitalised, influence*_teacher, Easter*_bunny, interest*-rate, eclipse*-sun, imbecile*-rejected, evening*-disaster, economy*_booming, easy*_exam 
APPENDIX B

Stimuli Used in Experiment 2

Each target word (in italics) is followed by its sentence frame.

Ordinary vowel-initial words

emerald, Emma thought the was pretty; angelic, The nice; interest, The in the book was great; odious, The

Jane put the ______ in the cupboard; eclipse, Kim watched the the ______; influence, The ______of the book was big; elf, The idiot, The ______ crossed the road.

Ordinary consonant-initialwords

mandolin, Ellie wanted to play the ; facial, Kathy liked the griffin, David thought the was scary; fairy, The flew away; mermaid, Nancy looked at the ; magical, The lamp was very special; society, Toby was in the ; candelabra, The companion, The was happy. was very big; snowflake, Robert looked at the

/j/-initial words with initial vowel letter utensil, The _-_____ was wet; The ____ moons were big; utility, The ;eulogy, Poppy read the

unicorn, Alex looked at the Uranus, The koala ate the ; universe, The ;unisex, The was very good; university, James went to the /j/-initial words with initial consonant letter

year, Tom went on holiday the after; yew, The bathroom was clean; eucalyptus, sailed on the sea; yam, Lucy ate the is very big; uniform, Oliver put on the boy was bad; eggcup, ; order, The girl forgot had a bow and arrow; yarn, The came loose; yeast, Sally put the ; yellow, John put on the was in the garden; yacht, The very loud; yearly, The party was fun; yeti, Sam was scared of the

\section{Ordinary " $h$ "-initial words}

historical, The _____ books were old; harness, Louise put the on the horse; hinge, The on the door was rusty; husband, The wife went to the ; harvest,

The festival was fun; headmaster, The was cross; house, Jenny went into the ; hedgehog, The

The

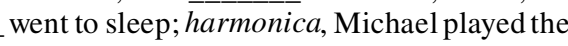
; harpy,

Silent " $h$ " words

hourly, The

bus was late; heirloom, Katie looked at the

The member smiled; hourglass, Peter broke the ; honesty, The ; honorary, portant; heir, Will was the to the throne; heiress, The was very beautiful; hour, The was long; honest, The girl was good; hours, The went slowly.

(Manuscript received October 15, 2002;

revision accepted for publication March 24, 2003.) 